\title{
A PLASTICITY MODEL FOR SIMULATION OF INDUSTRIAL POWDER COMPACTION PROCESSES
}

\author{
J. OLIVER, S. OLLER and J. C. CANTE \\ E.T.S. Enginyers de Camins, Canals i Ports, Universitat Politècnica de Catalunya, \\ Campus Nord U.P.C., Gran Capità s/n, Mòdul Cl 08034 Barcelona, Spain
}

\begin{abstract}
A constitutive model, based on large strain plasticity, for simulation of industrial powder compaction processes is presented. The elastic response is stated in terms of a hyperelastic model based on a hookean elastic free energy. Plastic response is defined in terms of a two parameter yield surface that evolves in terms of the relative density. Two different flow rules are considered and tested in front of some available experimental results. Application to the simulation of an actual powder-metallurgy compaction process is also shown. Copyright (C) 1996 Elsevier Science Ltd.
\end{abstract}

\section{INTRODUCTION}

Compaction processes play a fundamental role in powder metallurgy and structural ceramics manufacturing. In both cases the raw material is a very fine powder which is compacted, by different forming procedures, and then submitted to a sintering process (Sands and Shakespeare, 1966; Dixon and Clayton, 1971; Arunachalam and Roman, 1990). The most common compaction procedure is the so-called uniaxial compaction in which the powder in the die is compacted and shaped by the action of a set of punches which act sequentially along the vertical direction. Typical mean values of the relative powder density $\eta$ (measured with respect to the density after the sintering process) before and after the compaction are $\eta_{0}=0.4$ and $\eta_{\mathrm{f}}=0.95$, respectively, which means that the original volume occupied by the specimen reduces around 2.4 times. The main goal of the compaction process is to obtain a distribution of the density over the compacted specimen (from now on called the compact) as uniform as possible, in order to reach full effectiveness of the subsequent sintering process. A good prediction and control of the spring-back effects and the residual stresses, after loading removal, are also crucial for the goodness of the industrial manufacturing process. Design of a compaction process consists, essentially, in determining the sequence and relative displacements of die and punches in order to achieve such goals. The design process, which has to be done for any new type of piece to be manufactured, could be effectively improved by using a simulation tool, able to predict the mechanical response of the compact along the process. One of the main ingredients of such a code is an appropriated constitutive equation for the compact.

In the last few years, various constitutive models have been proposed for those purposes. They can be basically classified into:

- Microscopic models, also known as direct models (Turner, 1994; Tamura et al. 1994 ; Akisaya et al. 1994). They modelize each particle as a sphere (or approximated sphere) and the movement of many of them is computed accounting for their relative interaction. Although these models are thought to simulate the mechanical behaviour of the material, they fail to model real complex situations like the particles collapse during the process or the shape irregularity of local dislocations. Moreover, these simulations require long computational times since many particles have to be taken into account.

- Continuum or macroscopic models (Abouaf, 1985; Chenot et al. 1990; Bandstra et al. 1990; Weber and Brown, 1990; Gethin et al. 1992; Gethin and Lewis, 1994). They consider the mechanical behaviour of the compact in a continuum mechanics environment. 
This results in a set of equations describing the variation of density and, more generally, of all the variables of the problem according to the external pressure. This strategy comes with a numerical tool to solve the set of equations and thus compute the evolution of those variables. Up to date, a common characteristic of these models has been the use of the plasticity theory. The first models of this group were derived from others used for porous materials (Shima and Oyade, 1976; Weber and Brown 1990; Tomokazu et al., 1992; Riera et al. 1993; Coccoz et al. 1994) or frictional materials (Trasorras et al. 1989; Bandstra et al. 1990). Generally, the relative density has been chosen as a hardening variable, implying that various phenomena like the diffusion and the particle's relative sliding are not considered or are considered negligible. Basically, the differences between these models lie in the yield function definition and its evolution during the process.

The approach considered in this work lies on a constitutive model, devised for the development of a numerical tool for simulation of powder compaction processes (Oliver $e t$ al., 1992; Cante, 1995), in the light of previous experiences (Abouaf, 1985; Weber and Brown, 1990). Since the model is thought to be used in large scale computations, simplicity and computational efficiency is stressed in balance with its ability to capture the most relevant physical features of the process : distribution and evolution of density, strains and stresses. Large strain elasto-plasticity is chosen as a suitable constitutive equation for the problem together with dry friction models to capture friction effects at the walls of dies and punches.

The outline of the remains of the paper is as follows : in Section 2, justification is made about the use of an elasto-plastic constitutive equation. Section 3 is devoted to describe the constitutive model and some relevant aspects of the numerical integration. After describing, in Section 4, the chosen treatment for the contact and friction effects, Section 5 is devoted to the assessment of the model, in front of experimental tests, through numerical simulations.

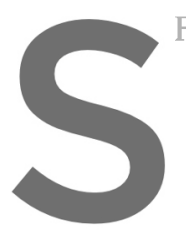
Finally some concludin

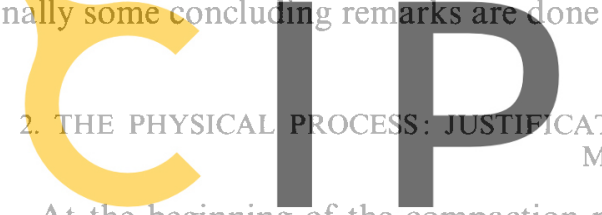

At the beginning of the compaction pro
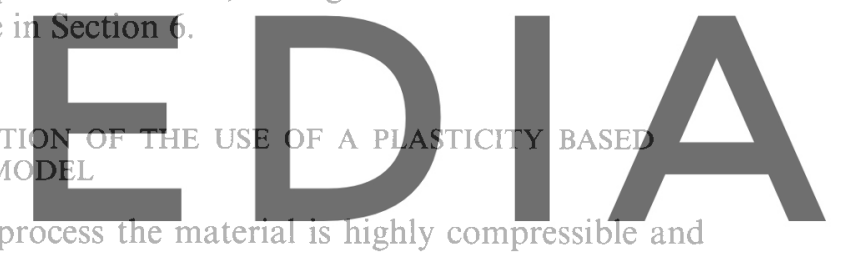
the strains are almost fully irrecoverable. From a macroscopic point of view the material

a low initial relative density $\eta_{0}$ defined as

$$
\eta_{0}=\left.\eta_{t}\right|_{t=0}=\left.\frac{\rho_{t}}{\rho_{\mathrm{s}}}\right|_{t=0} \approx 0.4
$$

where $\eta_{t}$ is the relative density at time $t, \rho_{t}$ is the apparent density at time $t$ and $\rho_{\mathrm{s}}$ is the solid density (after syntering). The apparent density evolves from the initial value $\rho_{0}$ to the final one $\rho_{\mathrm{s}}$ attained when the relative density tends to 1 .

The behaviour of the material along the compaction process can be explained at the grain level as the combination of two different behaviours concerning to (Sands and Shakespeare, 1966) : (i) the voids matrix, that evolves reducing the voids ratio, and (ii) the solid grains. During the first steps of the process the apparent strain comes from voids reduction, thus being irrecoverable. In later stages the number of grain contacts increases and variations of the apparent strain are also due to the elastic (recoverable) deformation of the grains. At final stages the rate of strain is almost fully elastic and the material behaves elastically (Fig. 1).

Large strain plasticity provides a framework to simulate the large apparent (grain + voids) irrecoverable deformation associated with voids reduction as well as the much smaller elastic and plastic strain in the powder particles. Appropriated definitions of the yield function and the flow rule can be derived to approach the fluid-like behaviour of the powder at the initial stages evolving towards a typical metallic behaviour at later stages of the compaction process. Section 3 is devoted to this subject. 

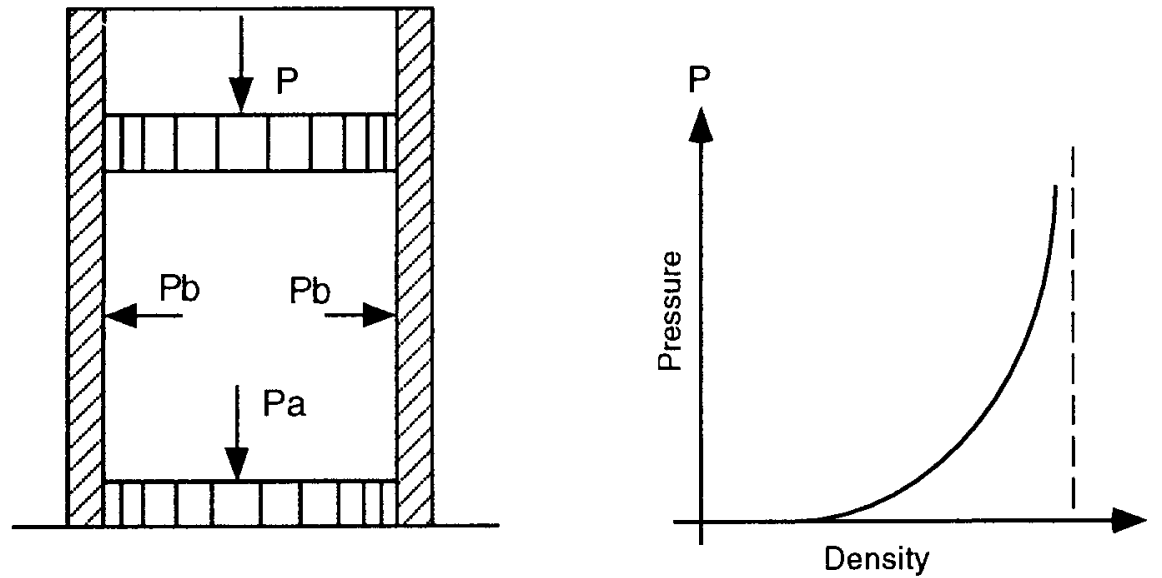

Fig. 1. Uniaxial compaction process.

3. CONSTITUTIVE MODEL

\subsection{Kinematics}

Let $\Omega \in \mathbb{R}^{N}(N=2,3)$ be the open and bounded domain occupied by the body at the reference (material) configuration and let $X \in \Omega$ be the referential description of a particle of the body. Let $[0, T]$ be the time-like interval of interest where $t$ should be understood as a monotonically increasing parameter describing the progression of the deformation process.

Let $F=\partial \varphi / \partial X$ be the deformation gradient, where $\varphi: \Omega \times[0, T] \rightarrow \mathbb{R}^{N}$ is the mapping that describes the movement of the body $\Omega$. Then we define $U(X, X)=\varphi(X, t)-X$ as the displacement field and

by Kröner (1960) and defined as:

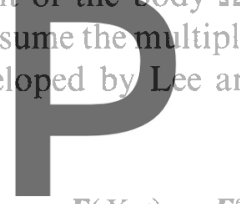

$$
F(X, t)=F^{\mathrm{e}}(X, t) F^{\mathrm{p}}(X, t)
$$
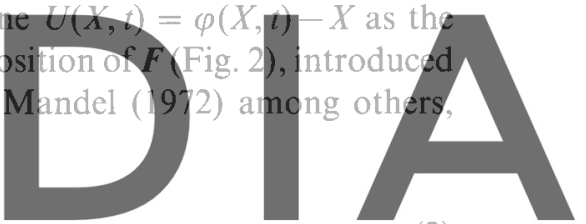

(2)

Register for free at https//www.scipedia, com to download the version without the watermark gradient tensor $F$.

Let us consider at the reference configuration $\Omega$ the Green-Lagrange strain tensor:

$$
\boldsymbol{E}=\frac{1}{2}\left(\boldsymbol{F}^{T} \cdot \boldsymbol{F}-\boldsymbol{G}\right)
$$

where $\boldsymbol{G}$ is the metric tensor at the reference configuration. Similarly, we consider, at the

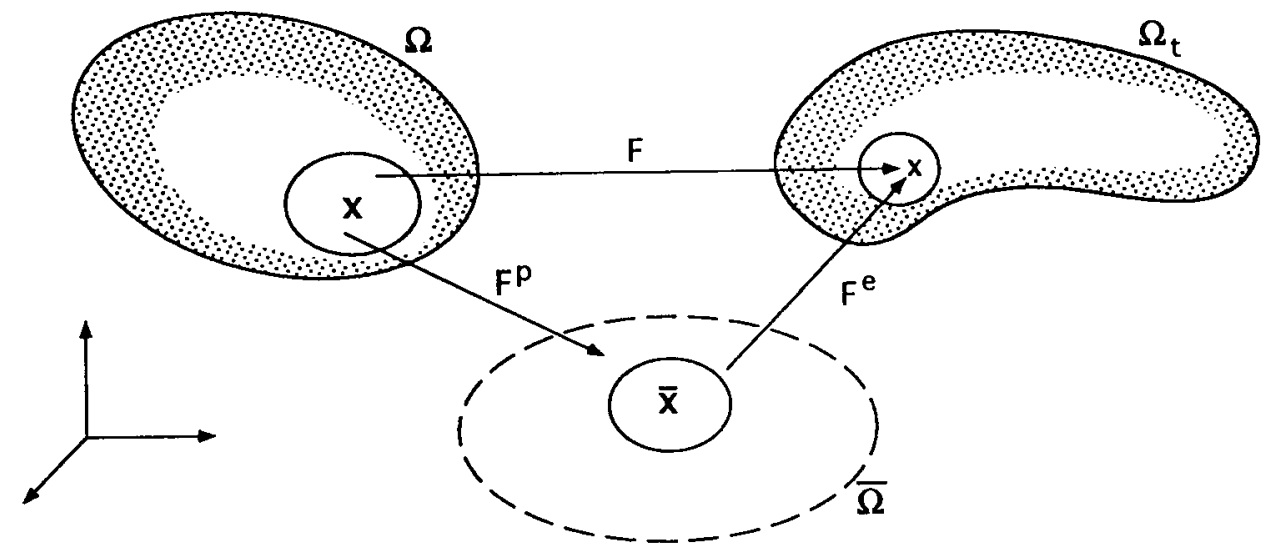

Fig. 2. Multiplicative decomposition. 
present configuration $\Omega_{t}$, the Almansi strain vector $e$ which can be related to $\boldsymbol{E}$ through classical push-forward $\phi_{*}(\cdot)$ and pull-back $\phi^{*}(\cdot)$ operators (Abraham et al. 1983) :

$$
e=\phi_{*}(\boldsymbol{E})=\boldsymbol{F}^{-T} \cdot \boldsymbol{E} \cdot \boldsymbol{F}^{-1}, \quad \boldsymbol{E}=\phi^{*}(e)=\boldsymbol{F}^{T} \cdot e \cdot \boldsymbol{F} .
$$

Then, it can be shown (Simo and Hughes, 1986; Lubliner, 1990) that the multiplicative decomposition of the deformation gradient tensor (2) leads to an additive decomposition of the strain at the present configuration given by:

$$
e=e^{\mathrm{e}}+e^{\mathrm{p}}
$$

\subsection{Constitutive equation}

3.2.1. Free energy and elastic response. In accordance with the assumptions of Mandel (1972) the local thermodynamic state is defined by means of the variables $e^{\mathbf{e}}$ and $q$, i.e. the elastic strain and the internal variables, respectively, corresponding to the present configuration. Then, the free energy density $\psi$ is defined, assuming uncoupled elastic behaviour, as:

$$
\psi=\psi\left(e^{\mathrm{e}}, q\right)=\psi^{\mathrm{e}}\left(e-e^{\mathrm{p}}\right)+\psi^{\mathrm{p}}(q)
$$

where $\psi^{\mathrm{e}}\left(e-e^{\mathrm{p}}\right)$ and $\psi^{\mathrm{p}}(q)$ correspond to the elastic and plastic counterparts of the free energy. In general plasticity models, the internal variables $q$ are used to describe the evolution of the yield function in order to model kinematic or isotropic hardening behaviours (Lubliner, 1990; Simo and Hughes, 1986). In the present approach, this evolution can be directly modelle
to any specific internal
be written as the elastic
elastic deformation sma
energy characterized by
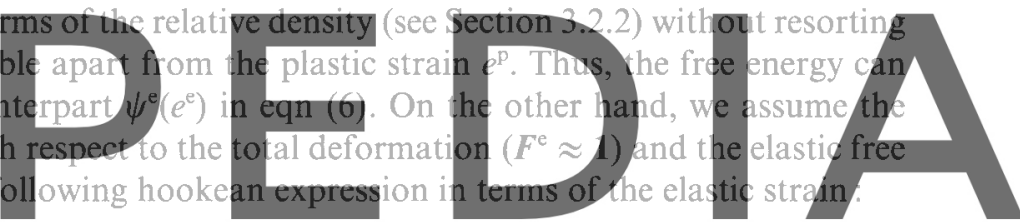

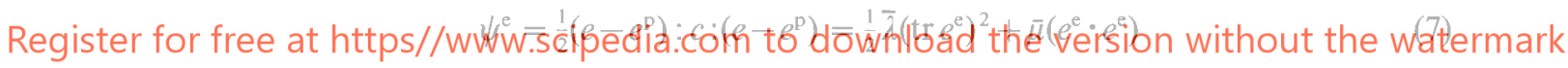

where $c=2 \bar{\mu} I+\bar{\lambda} \mathbb{1} \otimes \mathbb{I}$ is the elastic constitutive tensor evaluated at the present configuration, $I$ and $I$ are fourth and second order unit tensors, respectively, and $\bar{\lambda}$ and $\bar{\mu}$ are the Lame's constants which can be related to the Young's modulus and Poisson's ratio in a standard manner (Lubliner, 1990). It is also assumed an isotropic and hyperelastic response of the material so that the Kirchoff stress tensor $\tau$ at the present configuration reads :

$$
\tau=\frac{\partial \psi}{\partial e^{\mathrm{e}}}\left(e^{\mathrm{e}}, q\right)=c:\left(e-e^{\mathrm{p}}\right)=2 \bar{\mu}\left(e-e^{\mathrm{p}}\right)+\bar{\lambda} \operatorname{tr}\left[e-e^{\mathrm{p}}\right] \mathbf{1}
$$

Equation (8) can be moved to the reference configuration by performing pull-back operations of the type:

$$
\boldsymbol{S}=\phi^{*}(\tau)=\boldsymbol{F}^{-1} \cdot \tau \cdot \boldsymbol{F}^{-T}
$$

where $\boldsymbol{S}$ is the second Piola-Kirchoff stress tensor.

3.2.2. Relative density. Mass conservation can be formulated as:

$$
\rho_{t} \operatorname{Det} \boldsymbol{F}=\rho_{0}
$$

where $\rho_{t}$ and $\rho_{0}$ are the particle apparent densities at the present and the initial times, 
respectively. Equation (10) can be rewritten in terms of the relative densities by dividing both sides by the solid density leading to:

$$
\eta(X, t)=\eta_{t}(X)=\frac{\eta_{0}(X)}{\operatorname{Det}[F(X, t)]} .
$$

where $\eta_{0}$ is the initial relative density and $\eta_{l}$ is the relative density at time $t$.

3.2.3. Yield function. The yield function considered here follows the initial proposal of Kuhn and Downey (1971) later used by Weber and Brown (1990). A closed yield surface is described at the stress space in terms of the mean stress and the $J_{2}$ invariant of the deviatoric stresses. The initial yield surface is a point placed at the origin of the stress space. During the initial steps of the compaction process it evolves quite closely to the hydrostatic pressure axis to simulate the limited capability of the powder to carry shear stresses. In later stages it tends assymptotically to a Huber-Von Mises cylinder typical of metallic materials (Fig. 3). The analytical expression of such a yield surface at the present configuration is given by:

$$
\phi(\tau, \eta)=\|\operatorname{dev}[\tau]\|^{2}+a_{1}(\eta)\left(\frac{\operatorname{tr} \tau}{3}\right)^{2}-\frac{2}{3} a_{2}(\eta) \sigma_{\mathrm{y}}^{2} \leqslant 0
$$

\section{whose derivative with respect to the stresses reads:}
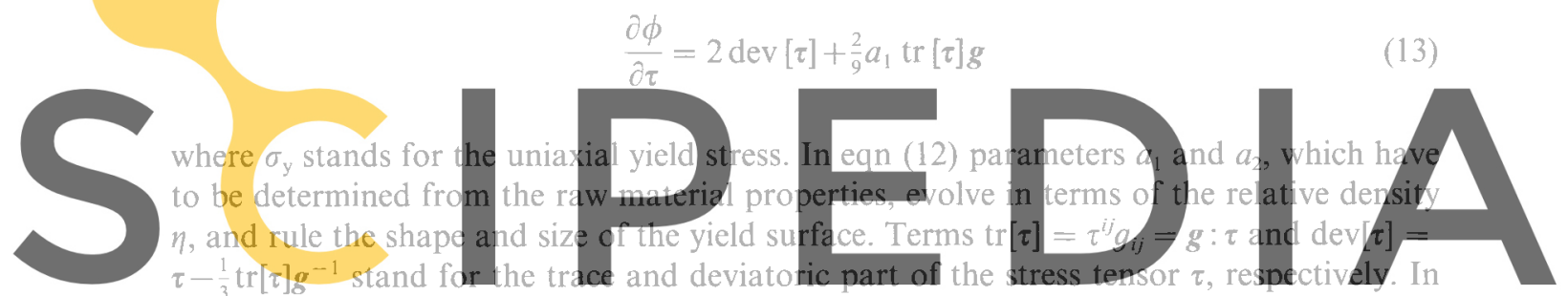

Fig. 3 the yield function and typical evolution of parameters $a_{1}$ and $a_{2}$ are plotted. Register for free at https//www.scipedia.com to download the version without the watermark
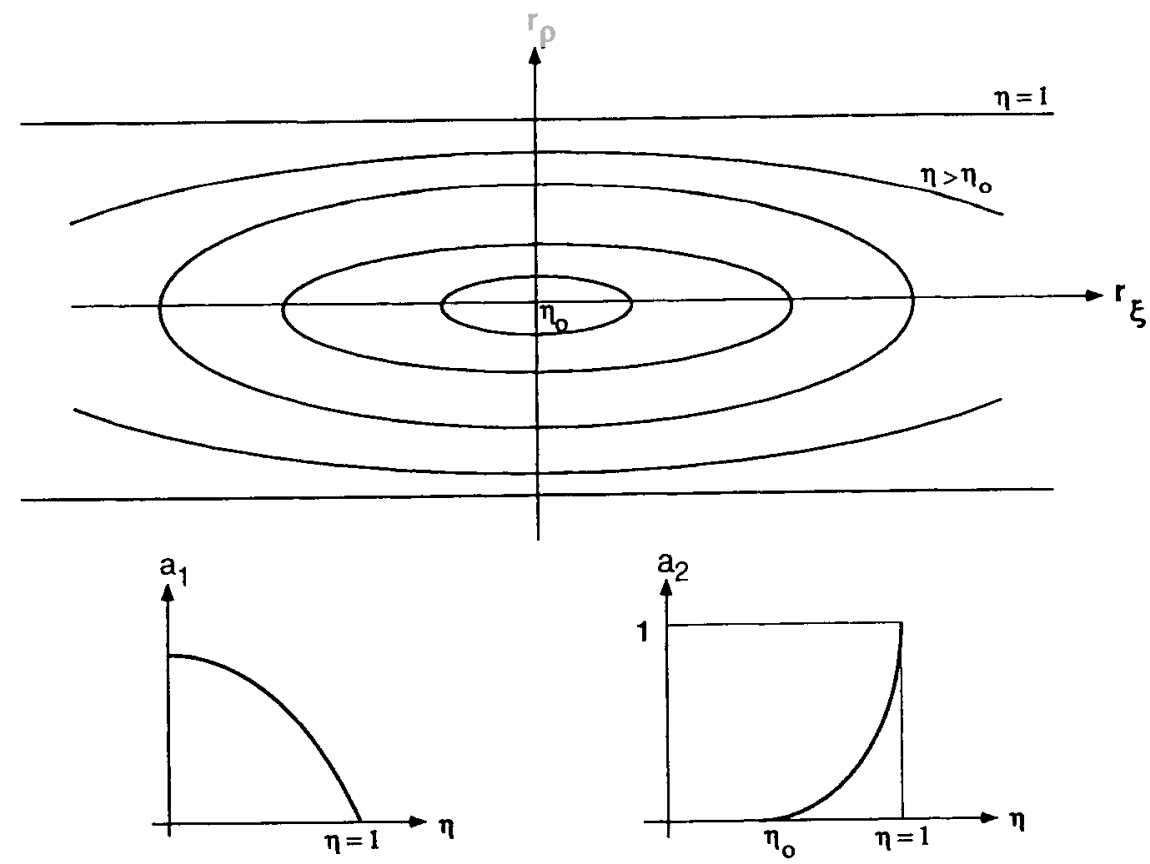

Fig. 3. Yield surface evolution and typical evolution of parameters $a_{1}$ and $a_{2} . r_{\rho}=\sigma_{y} \sqrt{\frac{2}{3}} a_{2}$, $r_{\xi}=\sigma_{y} \sqrt{\frac{2}{3}\left(a_{2} / a_{1}\right)}$ 
3.2.4. Flow rules. In this work two different flow rules have been considered:

(i) Non associated flow rule: the plastic flow is proportional to the elastic strain according to :

$$
L_{v} e^{\mathrm{p}}=\dot{\lambda} e^{\mathrm{e}}=\dot{\lambda}\left(e-e^{\mathrm{p}}\right)=\dot{\lambda} c^{-1}: \tau
$$

where $L_{v}(\cdot)$ stands for the Lie derivative (Abraham et al. 1983). Definition of the flow rule in terms of Lie derivatives fulfills the objectivity requirements for the plastic flow rule (Simo, 1988a, 1988b).

(ii) Associated flow rule:

$$
L_{v} e^{\mathrm{p}}=\dot{\lambda} \frac{\partial \phi}{\partial \tau}
$$

The plastic flow is supplemented by the classical Kuhn-Tucker conditions (Lubliner, 1990; Simo and Hughes, 1986) :

$$
\dot{\lambda} \geqslant 0 \quad \phi(\tau, \eta) \leqslant 0 \quad \dot{\lambda} \phi(\tau, \eta)=0
$$

\section{allowing for the determination of the plastic multiplier $\dot{\lambda}$.}

\subsection{Numerical integration of the constitutive equation}

Assuming the variables of the model at time $t_{n}$ and the incremental displacement field $\Delta U_{n+1}=U_{n+1}-U_{n}$ at time $t_{n+1}$ are known, the update of the different variables of the model at time $t_{n+1}$ is done as described in the next sections.
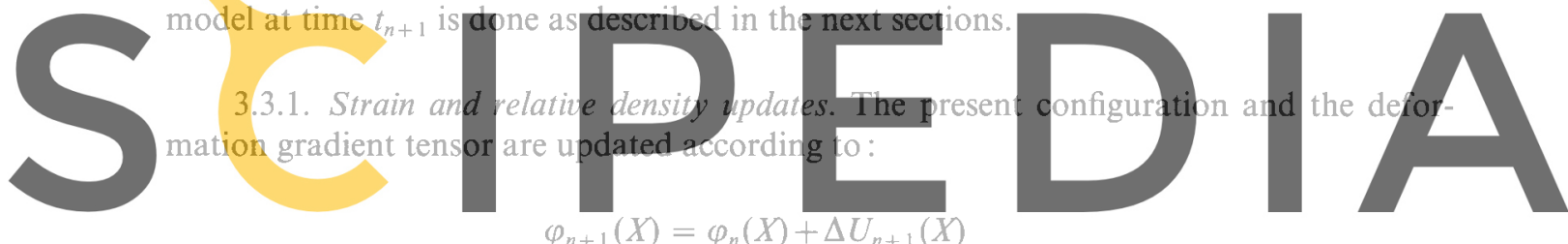

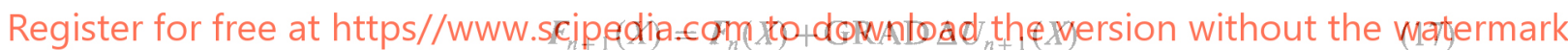

where GRAD stands for the material gradient operator. Then, from eqns (3) and (1i) the following updates of the strain field and relative density emerge:

$$
\begin{aligned}
& \boldsymbol{E}_{n+1}(X)=\frac{1}{2}\left(\boldsymbol{F}_{n+1}^{T} \boldsymbol{F}_{n+1}-\boldsymbol{G}\right) \\
& \eta_{n+1}(X)=\frac{\eta_{0}(X)}{\operatorname{det} \boldsymbol{F}_{n+1}(X)} .
\end{aligned}
$$

3.3.2. Plastic strain update: non-associated flow rule. An implicit (backward Euler) numerical integration of eqn (14) leads to (Cante, 1995):

$$
e_{n+1}^{\mathrm{p}}(x)=\tilde{e}_{n}^{\mathrm{p}}(x)+\Delta \lambda_{n+1}\left[e_{n+1}(x)-e_{n+1}^{\mathrm{p}}(x)\right]
$$

where $\Delta \lambda_{n+1}=\Delta t \dot{\lambda}\left(t_{n+1}\right)$. Term $\tilde{e}_{n}^{\mathrm{p}}$ is computed as $\tilde{\boldsymbol{e}}_{n}^{\mathrm{p}}=\phi^{n+1}{ }_{*}\left[\phi_{n}^{*}\left(e_{n}^{\mathrm{p}}\right)\right]$ where $\phi_{n}^{*}$ and $\phi^{n+1}{ }_{*}$ stand for pull back and push forward operators at times $t_{n}$ and $t_{n+1}$ respectively.

Equation (19) can be solved for $e_{n+1}^{\mathrm{p}}$ leading to the following closed form expression in terms of the plastic multiplier:

$$
e_{n+1}^{\mathrm{p}}(x)=\left(1-\alpha_{n+1}\right) e_{n+1}(x)+\alpha_{n+1} \tilde{e}_{n}^{\mathrm{p}}(x)
$$

where: 


$$
\alpha_{n+1}=\frac{1}{1+\Delta \lambda_{n+1}} \quad e_{n+1}=\phi_{*}^{n+1}\left(E_{n+1}\right) .
$$

Finally, from eqn (20) the stresses can be evaluated resorting to eqn (8) as:

$$
\tau_{n+1}=c:\left(e_{n+1}-e_{n+1}^{p}\right)
$$

The update of the plastic strain and the stresses given by eqns (20)-(22) requires the determination of the plastic multiplier increment $\Delta \lambda_{n+1}$ which is done by the following elastic-predictor plastic-corrector algorithm (Simo and Hughes, 1986):

- Elastic predictor :

Assuming no evolution of the plastic strain during the considered time step we define the trial elastic strain as:

$$
e_{n+1}^{e^{\text {trial }}}=e_{n+1}-\tilde{e}_{n}^{\mathrm{p}}
$$

and the corresponding predicted values for the stress field and yield function:

$$
\begin{aligned}
\tau_{n+1}^{\text {trial }} & =c: e_{n+1}^{e^{\text {trial }}} \\
\phi_{n+1}^{\text {trial }} & =\phi\left(\tau_{n+1}^{\text {trial }}, \eta_{n+1}\right) \geqslant \phi_{n+1}=\phi\left(\tau_{n+1}, \eta_{n+1}\right) .
\end{aligned}
$$

- Plastic corrector:

Case I: If $\phi_{n+1}^{\text {trial }}<0$, then, from eqn (24) $\phi_{n+1}<0$. In this case the Kuhn-Tucker conditions (16) lead to $\Delta \lambda_{n+1}=0$, so that, from eqns (20) and (22) there is no evolution of the plastic strain and
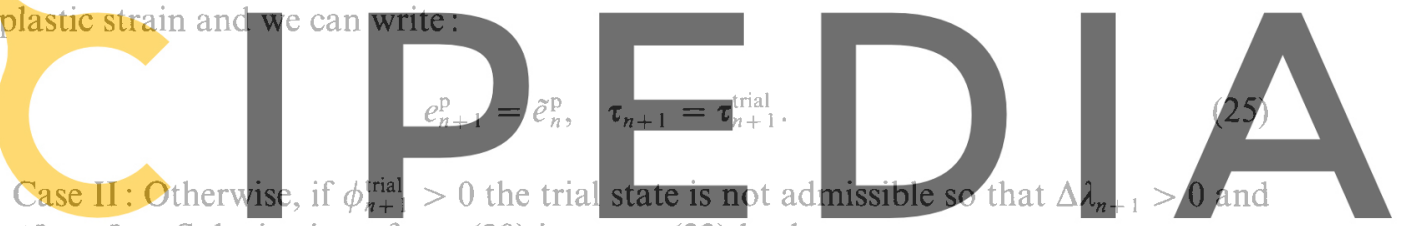

then $\tilde{e}_{n}^{\mathrm{p}} \neq e_{n+1}^{\mathrm{p}}$. Substitution of eqn (20) into eqn (22) leads to:

Register for free at https//www.scipedia.com to download the version without the watermark $\tau_{n+1}=\alpha_{n+1} \tau_{n+1}^{\text {trial }}$.

Condition $\Delta \lambda_{n+1}>0$ implies that in eqn (16) $\phi_{n+1}=0$ (consistency condition, Simo and Hughes, 1986), so that

$$
\phi\left(\alpha_{n+1} \tau_{n+1}^{\text {trial }}, \eta_{n+1}\right)=0 .
$$

Finally, from eqns (12) and (27) straightforward computations lead to the following closed form determination of $\alpha_{n+1}$ as :

$$
\alpha_{n+1}^{2}=\frac{\frac{2}{3} a_{2}\left(\eta_{n+1}\right) \sigma_{y}^{2}}{\left\|\operatorname{dev} \tau_{n+1}^{\text {trial }}\right\|^{2}+\frac{1}{9} a_{1}\left(\eta_{n+1}\right)\left[\operatorname{tr} \tau_{n+1}^{\text {trial }}\right]^{2}} .
$$

Once $\alpha_{n+1}$ is determined the plastic multiplier $\Delta \lambda_{n+1}$ can be solved from eqn (21a).

3.3.3. Plastic strain update: associated flow rule. Implicit integration of eqn (15) leads now to:

$$
e_{n+1}^{\mathrm{p}}=\tilde{e}_{n}^{\mathrm{p}}+\Delta \lambda_{n+1} \frac{\partial \phi_{n+1}}{\partial \tau_{n+1}} \quad \Delta \lambda_{n+1}=\Delta t \dot{\lambda}\left(t_{n+1}\right)
$$

and, after substitution of eqn (13), eqn (29) reads: 


$$
e_{n+1}^{\mathrm{p}}=\tilde{e}_{n}^{\mathrm{p}}+2 \Delta \lambda_{n+1}\left[\operatorname{dev}\left[\tau_{n+1}\right]+\frac{1}{9} a_{1} \operatorname{tr}\left[\tau_{n+1}\right] g\right]
$$

where $\boldsymbol{g}$ is the metric tensor at the present configuration. The next steps are similar to the ones considered for the non-associated flow rule case. Equations (22) and (30) supplemented by the Kuhn-Tucker conditions (16) lead, through the predictor-corrector algorithm scheme of Section 3.3.2, to the following closed form solution for the stress field (Cante, 1995) :

$$
\boldsymbol{\tau}_{n+1}= \begin{cases}\tau_{n+1}^{\text {trial }} & \phi\left(\tau_{n+1}^{\text {trial }}, \eta_{n+1}\right)<0 \\ \alpha_{n+1} \operatorname{dev}\left[\tau_{n+1}^{\text {tria) }}\right]+\beta_{n+1} p_{n+1}^{\text {trial }} \mathbf{1} & \phi\left(\tau_{n+1}^{\text {trial }}, \eta_{n+1}\right) \geqslant 0\end{cases}
$$

where

$$
p_{n+1}^{\text {trial }}=\frac{1}{3} \operatorname{tr}\left[\tau_{n+1}^{\text {trial }}\right], \quad \alpha_{n+1}=\frac{1}{1+4 \bar{\mu} \Delta \lambda_{n+1}}, \quad \beta_{n+1}=\frac{1}{1+2 \kappa a_{1} \Delta \lambda_{n+1}}
$$

and $\kappa=\bar{\lambda}+(2 / 3) \bar{\mu}$. Substitution of the stress field $\tau_{n+1}$ given by eqn (31b) into the yield condition $\phi\left(\tau_{n+1}, \eta_{n+1}\right)=0$ (consistency condition) leads, after same algebraic computations (Cante, 1995), to the following polynomical expression:

$$
\beta_{n+1}^{2}\left\|\operatorname{dev} \tau_{n+1}^{\text {trial }}\right\|^{2}+\alpha_{n+1}^{2}\left(p_{n+1}^{\text {trial }}\right)^{2}-\frac{2}{3} a_{2}\left(\eta_{n+1}\right) \sigma_{y}^{2}=0
$$

which can be solved for $\Delta \lambda_{n+1}$ considering eqns (32). In Boxes 1 and 2, the algorithms for the associated and non-associated flow rule cases, respectively, are summarized. Also, the
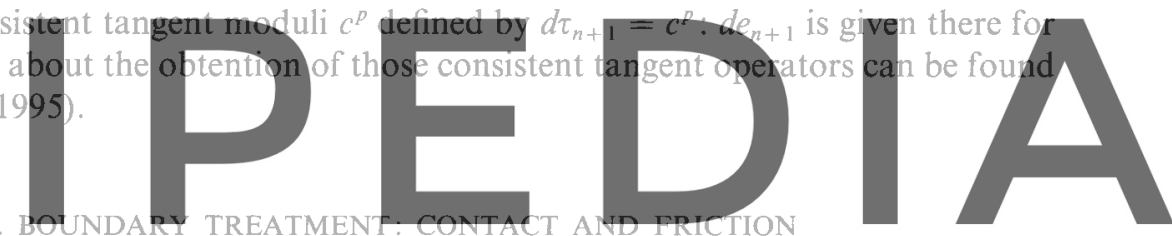

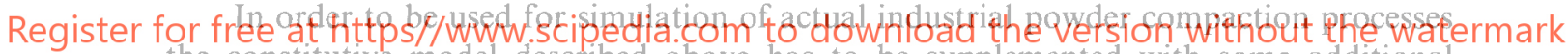
the constitutive model described above has to be supplemented with some additional ingredients referring to the boundary conditions.

Confinement of the powder by dies and punches implies the addition of a contact model for the solid. Two main options are available at this point : penalty methods, which have the advantages of easiness of implementation and preservation of the quadratic convergence of Newton schemes for the solver, and augmented-lagrangian methods (Simo and Laursen, 1992; Laursen and Simo, 1993) which have robustness as the main advantage. For the considered powder compaction process large changes in the material stiffness occurring along the process, substantially affect the robustness of the penalty methods and make the second family of methods more convenient. Thus, a unilateral contact scheme based on an augmented-lagrangian approach has been used for the simulations presented below (Cante, 1995).

Another relevant aspect of compaction processes is the friction between the compact, and the walls of dies and punches. Several options are also available here (Curnier, 1984), but in order to check the reliability of the proposed constitutive equation, a dry friction model (Coulomb-type friction) has been considered sufficient to capture the more relevant aspects of friction. Further details about the considered contact and friction models are given elsewhere (Cante, 1995).

\section{MODEL ASSESSMENT: NUMERICAL EXPERIMENTS}

The constitutive equation presented above, together with the described methodology to account for contact-friction effects, have been implemented in a non-linear finite element 


\section{Box 1}

Non associated flow rule: numerical integration

1. Updates.

$$
\begin{aligned}
& \boldsymbol{\varphi}_{n+1}=\boldsymbol{\varphi}_{n}+\Delta \boldsymbol{U}_{n+1}, \quad \boldsymbol{F}_{n+1}=\boldsymbol{F}_{n}+\mathrm{GRAD} \Delta \boldsymbol{U}_{n+1} \\
& \boldsymbol{E}_{n+1}=\frac{1}{2}\left(\boldsymbol{F}_{n+1}^{T} \boldsymbol{F}_{n+1}-\boldsymbol{G}\right), \quad \eta_{n+1}=\frac{\eta_{0}}{\operatorname{det} \boldsymbol{F}_{n+1}} .
\end{aligned}
$$

2. Elastic predictor.

$$
\tau_{n+1}^{\text {trial }}=c: e_{n+1}^{e^{\text {riral }}} \quad \text { where } \quad e_{n+1}^{e^{\text {riral }}}=e_{n+1}-\tilde{e}_{n}^{p} \quad \tilde{e}_{n}^{p}=\boldsymbol{F}_{n+1}^{-T} \boldsymbol{F}_{n}^{T} e_{n}^{p} \boldsymbol{F}_{n} \boldsymbol{F}_{n+1}^{-1} .
$$

3. Yield condition and plastic corrector.

If $\phi\left(\tau_{n+1}^{\text {trial }}, \eta_{n+1}\right) \leqslant 0$ Then

$$
\begin{aligned}
& \tau_{n+1}=\tau_{n+1}^{\text {trial }} \\
& e_{n+1}^{p}=\tilde{e}_{n}^{p}
\end{aligned}
$$

else

$$
g_{n+1}^{\text {trial }}=\left\|\operatorname{dev} \tau_{n+1}^{\text {trial }}\right\|^{2}+\frac{1}{9} a_{1} \operatorname{tr}^{2}\left[\tau_{n+1}^{\text {trial }}\right]
$$
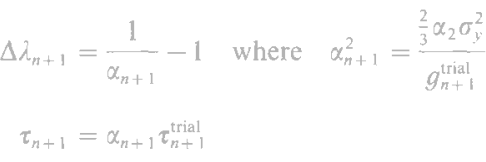

$e_{n+1}^{p}=\left(1-\alpha_{n+1}\right) e_{n+1}+\alpha_{n+1} \tilde{e}_{n}^{p}$

Consistent tangent moduli
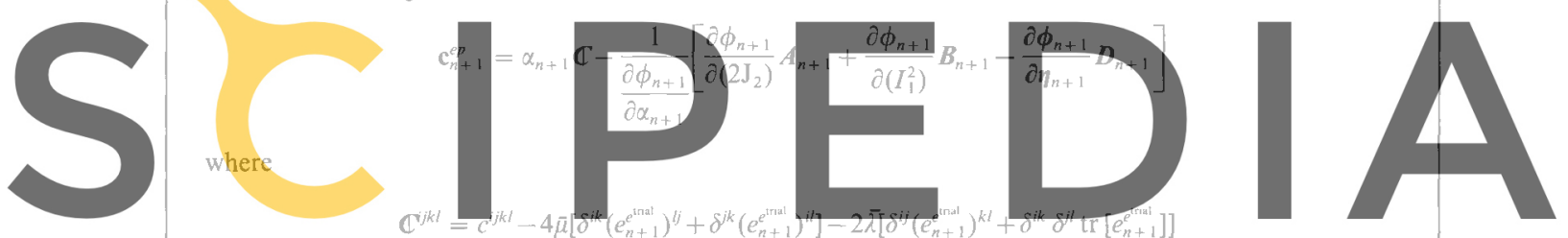

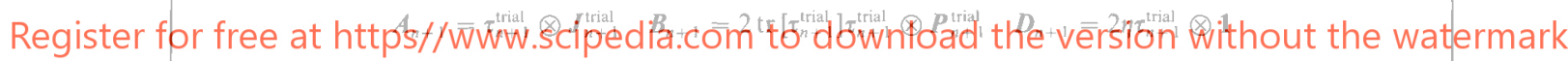

\section{$J_{n+1}^{\text {trial }}=2 \operatorname{dev}\left[\tau_{n+1}^{\text {trial }}\right] \cdot \tau_{n+1}^{\text {trial }}+\operatorname{dev}\left[\tau_{n+1}^{\text {trial }}\right]: \mathbb{C}_{n+1}$}

$\boldsymbol{P}_{n+1}^{\text {trial }}=2 \tau_{n+1}^{\text {trial }}+\mathbf{1}: \mathbb{C}_{n+1}$

code. In order to evaluate the capability of the whole approach to simulate powder compaction processes some tests have been driven and the corresponding numerical results are compared with available experimental results in the next sections.

\subsection{Assessment of the flow rule}

Doremus et al. (1994) performed a set of compaction experiments using the triaxial press schematically plotted in Fig. 4b. Both isostatic compaction (hydrostatic pressure) and triaxial tests were driven. The raw material was iron powder with particle sizes ranging from $10 \mu \mathrm{m}$ to $100 \mu \mathrm{m}$. The compacted specimens had an initial height $h=24 \mathrm{~mm}$ and diameter $D=20 \mathrm{~mm}$. Triaxial tests consisted of an initial isostatic compaction step, up to the value $\sigma_{r}=400 \mathrm{MPa}$ for the hydrostatic pressure, followed by a subsequent uniaxial compaction step carried out by keeping constant $\sigma_{r}$ and increasing the vertical stress $\sigma_{z}$ up to a maximum value of $\sigma_{z}=1250 \mathrm{MPa}$ (Fig 4a).

In the simulations the following values are taken for the material properties:

$$
\text { Young's modulus }=2.0 \times 10^{3} \mathrm{MPa}
$$

Poisson's ratio $=0.37$ 
Initial apparent density $=3.67 \mathrm{gr} / \mathrm{cm}^{3}$

Solid density $=7.5 \mathrm{gr} / \mathrm{cm}^{3}$

Initial relative apparent density $=\eta_{0}=3.67 / 7.5=0.489$

Yield stress $=90 \mathrm{MPa}$

$$
a_{1}(\eta)=\frac{1-\eta^{2}}{2+\eta^{2}} \quad a_{2}(\eta)=\left[\frac{\eta-\eta_{0}}{1-\eta_{0}}\right]^{2.7} .
$$

In Fig. 5, corresponding to the isostatic compression step, experimental and numerical results (density vs pressure) are compared for both the associated and non-associated flow rules. Good agreements are found for both cases and no substantial difference due to the chosen flow rule is observed.

\section{Box 2}

Associated flow rule: numerical integration

1. Updates.

$$
\begin{aligned}
& \varphi_{n+1}=\varphi_{n}+\Delta U_{n+1}, \quad F_{n+1}=F_{n}+\operatorname{GRAD} \Delta U_{n+1} \\
& \boldsymbol{E}_{n+1}=\frac{1}{2}\left(\boldsymbol{F}_{n+1}^{T} \boldsymbol{F}_{n+1}-G\right), \quad \eta_{n+1}=\frac{\eta_{0}}{\operatorname{det} \boldsymbol{F}_{n+1}} .
\end{aligned}
$$

2. Elastic predictor.
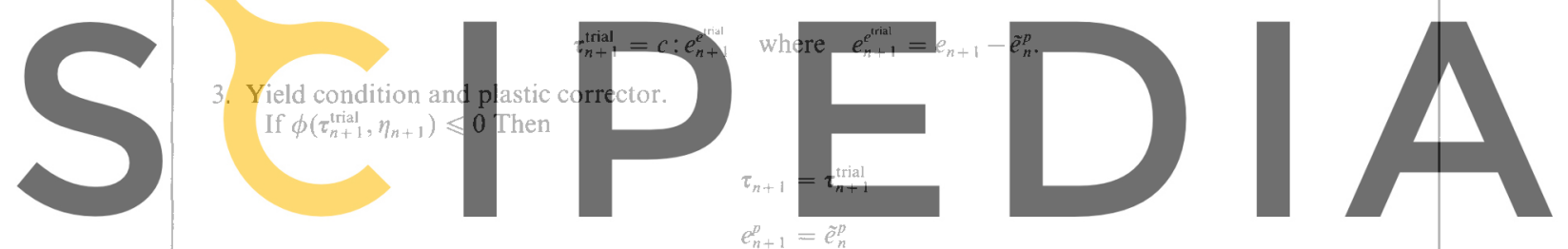

Register for freelsat https//www.scipedia.com to download the version without the watermark

\section{$p_{n+1}^{\text {trial }}=\frac{1}{3} \operatorname{tr}[\tau]_{n+1}^{\text {trial }}$}

$\Delta \lambda_{n+1}=$ positive root of (33)

$$
\begin{aligned}
\alpha_{n+1} & =\frac{1}{1+\overline{4 \mu} \Delta \lambda_{n+1}} \beta_{n+1}=\frac{1}{1+2 \kappa a_{1} \Delta \lambda_{n+1}} \\
\tau_{n+1} & =\alpha_{n+1} \operatorname{dev} \tau_{n+1}^{\text {trial }}+\beta_{n+1} p_{n+1}^{\text {trial }} \mathbf{1} \\
e_{n+1}^{p} & =\tilde{e}_{n}^{p}+2 \Delta \lambda_{n+1}\left[\operatorname{dev} \tau_{n+1}+\frac{1}{9} a_{1} \operatorname{tr}[\tau]_{n+1} \mathbf{1}\right] .
\end{aligned}
$$

4. Consistent tangent moduli.

$$
\begin{aligned}
c_{n+1}^{e p}= & \alpha_{n+1} \Lambda_{n+1}+\frac{1}{3} \beta_{n+1} 1 \otimes P_{n+1}^{\text {trial }}-\frac{2}{3} \beta_{n+1} \operatorname{tr}[\tau] \boldsymbol{I} \\
& +G_{\alpha \beta}\left[\frac{\partial \phi_{n+1}}{\partial\left(2 J_{2}\right)} A_{n+1}+\frac{\partial \phi_{n+1}}{\partial\left(I_{1}^{2}\right)} B_{n+1}-\frac{\partial \phi_{n+1}}{\partial \eta_{n+1}} D_{n+1}\right] \\
\Lambda_{n+1}= & \mathbb{C}_{n+1}+\frac{2}{3} \operatorname{tr}\left[\boldsymbol{\tau}_{n+1}^{\text {trial }}\right] \boldsymbol{I}-\frac{1}{3} \mathbf{1} \otimes P_{n+1}^{\text {trial }} .
\end{aligned}
$$

Where $\boldsymbol{C}, \boldsymbol{P}_{n+1}^{\text {trial }}, \boldsymbol{J}_{n+1}^{\text {trial }}$ are defined in Box 1 , and :

$$
\begin{aligned}
\boldsymbol{A}_{n+1} & =\boldsymbol{q}_{n+1}^{\text {trial }} \otimes \boldsymbol{J}_{n+1}^{\text {trial }} \quad \boldsymbol{B}_{n+1}=2 \operatorname{tr}\left[\tau_{n+1}^{\text {trial }}\right] \boldsymbol{q}_{n+1}^{\text {trial }} \otimes \boldsymbol{P}_{n+1}^{\text {trial }} \quad \boldsymbol{D}_{n+1}=\eta_{n+1} \boldsymbol{q}_{n+1}^{\text {trial }} \otimes \mathbf{1} \\
\boldsymbol{q}_{n+1}^{\text {trial }} & =4 \bar{\mu} \alpha_{n+1}^{2} \operatorname{dev} \tau_{n+1}^{\text {trial }}+2 \kappa a_{1} \beta_{n+1}^{2} p_{n+1}^{\text {trial }} \mathbf{1} \\
G_{\alpha \beta} & =\frac{1}{4 \bar{\mu} \alpha_{n+1}^{2} \frac{\partial \phi}{\partial \alpha}+2 \kappa a_{1} \beta_{n+1}^{2} \frac{\partial \phi}{\partial \beta}} .
\end{aligned}
$$




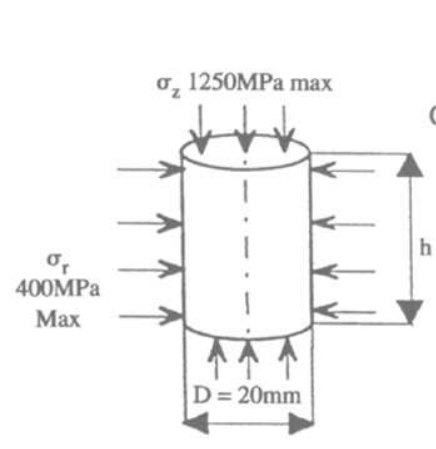

(a)

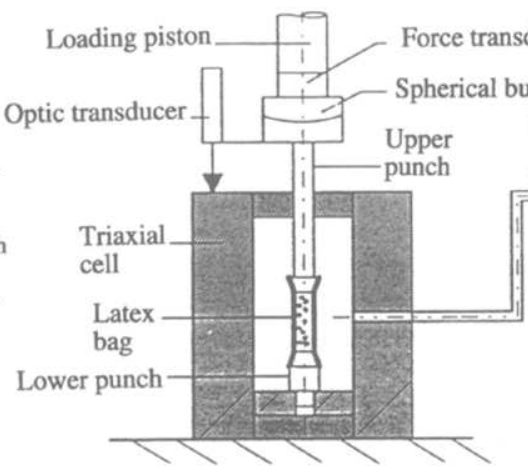

(b)

\section{sducer}

bushing

High pressure transducer

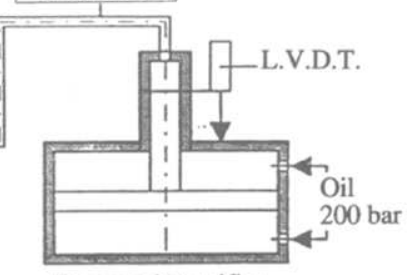

Pressure intensifier

Fig. 4. (a) Initial geometry of the sample and maximum applied triaxial stress. (b) Schematic diagram of the triaxial cell (Ernst and Barnekow, 1994).

(a)

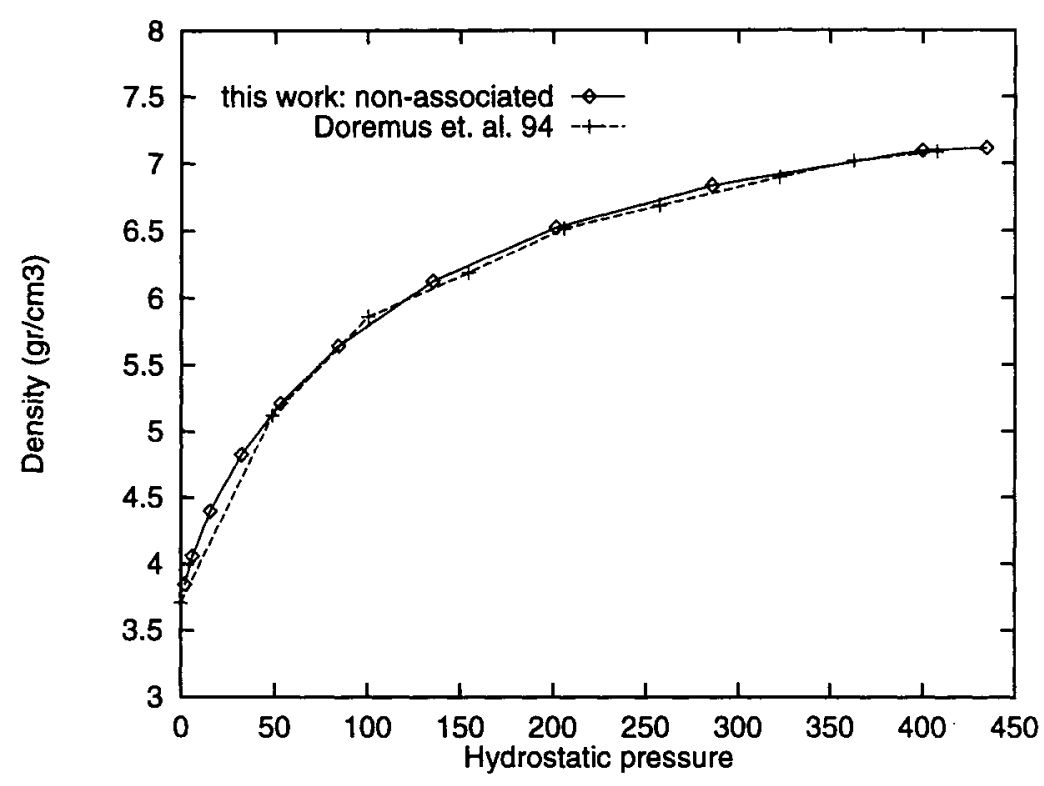

(b)

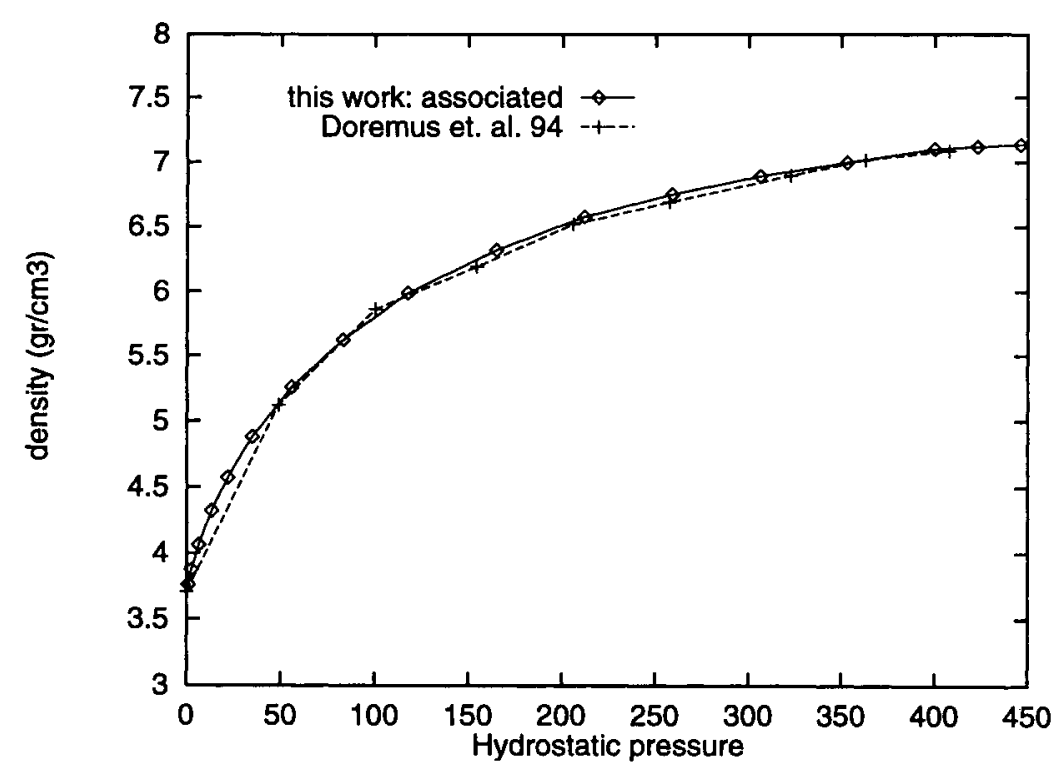

Fig. 5. Isostatic compaction test. (a) Non-associated flow rule. (b) Associated flow rule. 


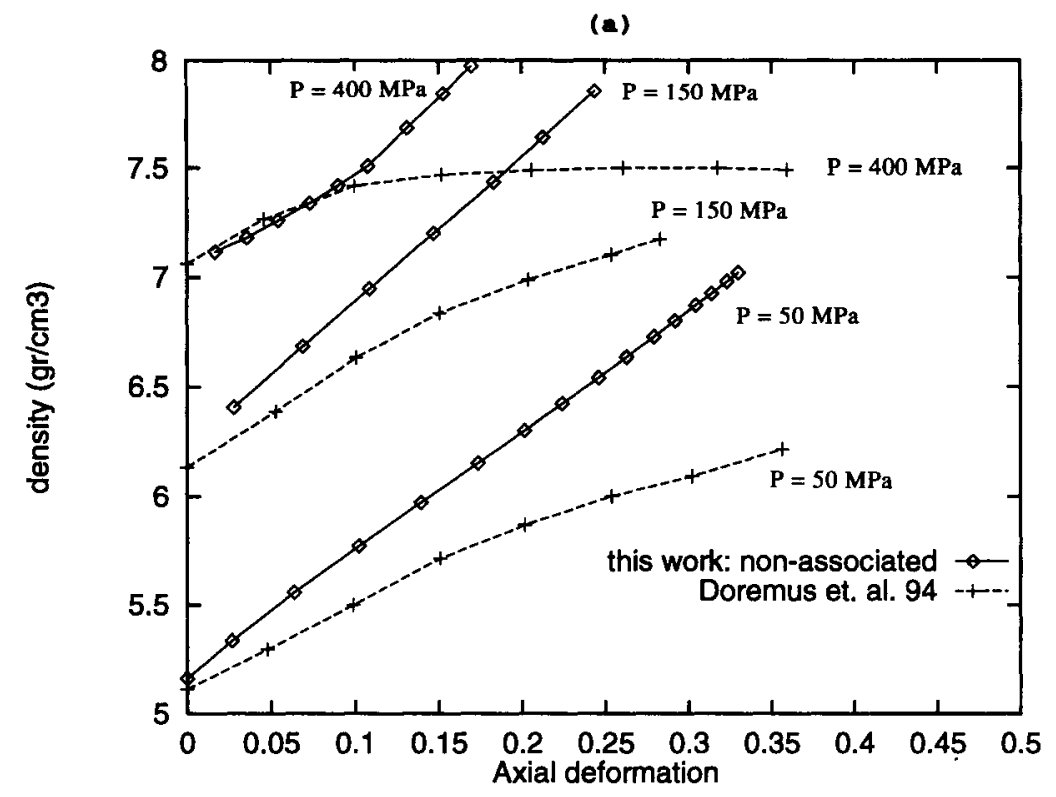

(b)

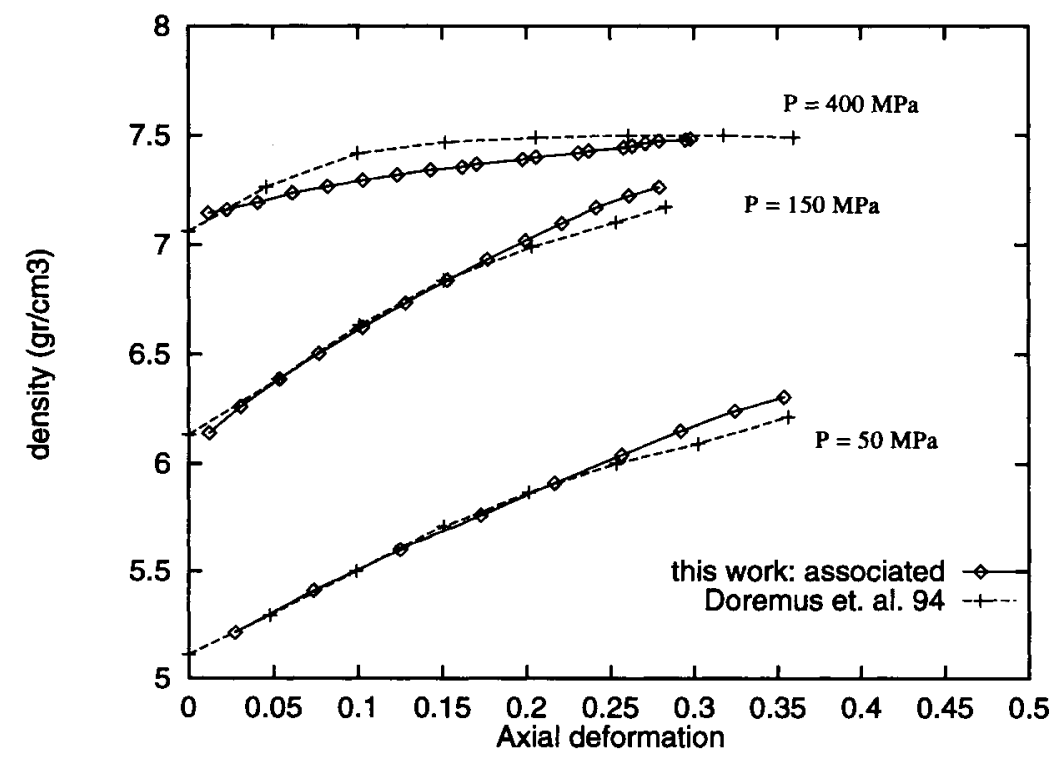

Fig. 6. Triaxial test. (a) Non-associated flow rule. (b) Associated flow rule.

Figure 6 corresponds to the complete triaxial (isostatic + uniaxial compression) test. Density vs uniaxial strain curves are plotted for both flow rules and for different values of the hydrostatic pressure $p$ attained at the end of the isostatic compression step. In these figures the uniaxial strain is computed as $\left(L_{f}-L_{0}\right) / L_{0}$ where $L_{0}$ and $L_{f}$ are the initial and current heights of the specimen, respectively.

As far as numerical simulations are concerned, results of Fig. 6 show very different behaviour for the non-associated and associated flow rules, the results fitting much better the experiments in the second case (Fig. 6b). This fact shows that the actual plastic flow, for the considered type of metallic powder, is much better approached by a flow normal to the yield surface, i.e. the one given by the associated flow rule of eqn (15), even at early stages of the compaction process.

Results reported by Ernst and Barnekow (1994) are used to perform some additional assessments of the associated flow rule. The considered cylindrical specimens had a diameter 


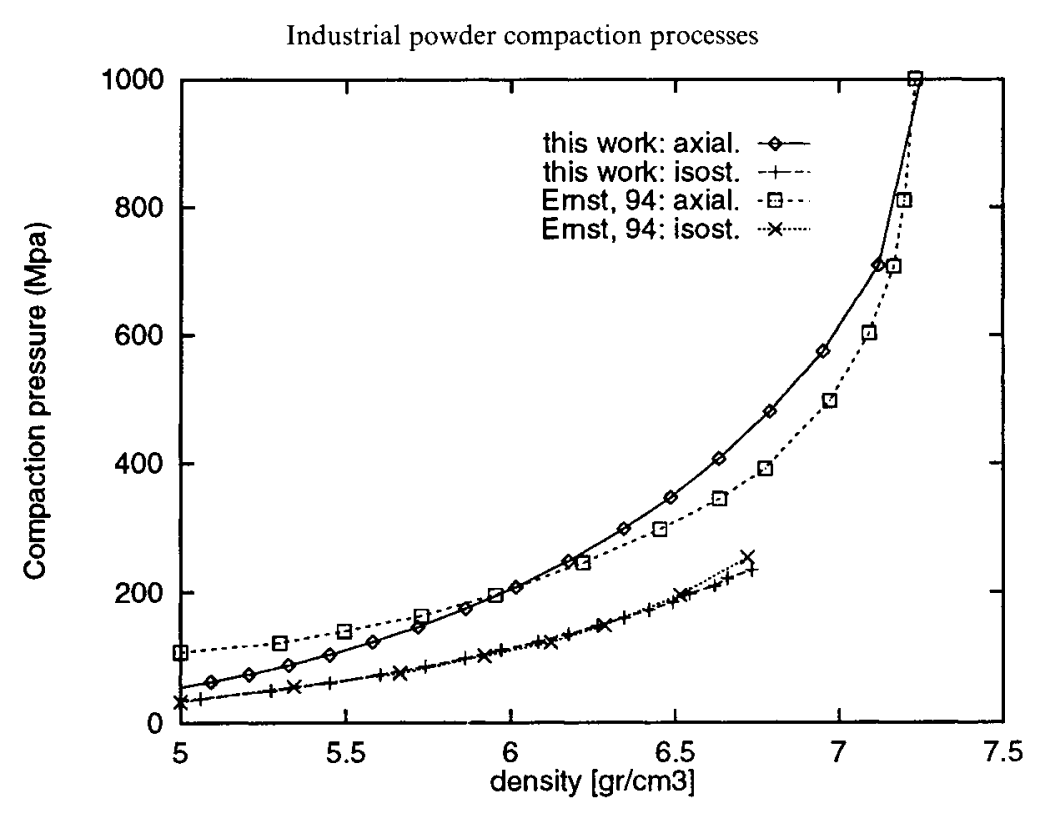

Fig. 7. Isostatic and uniaxial compaction process-compaction pressure vs apparent density.

of $14.3 \mathrm{~mm}$ and an initial height of $80 \mathrm{~mm}$. The raw material was 100.29 (Höganäs) with $1 \%$ Microwax $\mathrm{C}$ (Hoescht) for which the following values are taken as material properties:

$$
\begin{aligned}
\text { Young's modulus } & =5.0 \times 10^{4} \mathrm{MPa} \\
\text { Poisson's ratio } & =0.37 \\
\text { Initial apparent density } & =\rho_{0}=2.94 \mathrm{gr} / \mathrm{cm}^{3} \\
\text { Solid density } & =\rho_{\mathrm{s}}=7.35 \mathrm{gr} / \mathrm{cm}^{3} \\
\text { Initial relative apparent density } & =\eta_{0}=2.94 / 7.35=0.4 \\
\text { Yield stress } & =170 \mathrm{MPa} \\
a_{1}(\eta)=\left[\frac{1-\eta^{2}}{2+\eta^{2}}\right]^{0.3} \quad a_{2}(\eta) & =\left[\frac{\eta-\eta_{0}}{1-\eta_{0}}\right]^{5.4} .
\end{aligned}
$$

An isostatic compaction process was driven up to reach a pressure of $250 \mathrm{MPa}$. Also, a purely uniaxial compaction process was considered to reach a vertical pressure of 900 $\mathrm{MPa}$. Comparisons between numerical and experimental results are presented in Fig. 7, in terms of the vertical pressure vs apparent density, which show quite satisfactory agreements.

\subsection{Numerical simulation of an actual industrial compaction process}

The next example refers to the simulation of a multi-level compaction process (Krauss et al. 1991). The compact specimen is a bearing used in the automotive industry whose geometry (axisymmetric) is shown in Fig. 8. The initial and final shapes are plotted in the figure with dashed and full lines, respectively. Characteristic sizes of the specimen are as follows

$$
\begin{array}{ll}
R_{1}=16.1 \mathrm{~mm} & H_{1}=40.3 \mathrm{~mm} \\
R_{2}=22.4 \mathrm{~mm} & H_{2}=9.40 \mathrm{~mm} \\
R_{3}=27.7 \mathrm{~mm} & H_{3}=17.8 \mathrm{~mm} \\
R_{4}=32.1 \mathrm{~mm} & H_{4}=60.0 \mathrm{~mm} \\
& H_{5}=7.50 \mathrm{~mm} .
\end{array}
$$




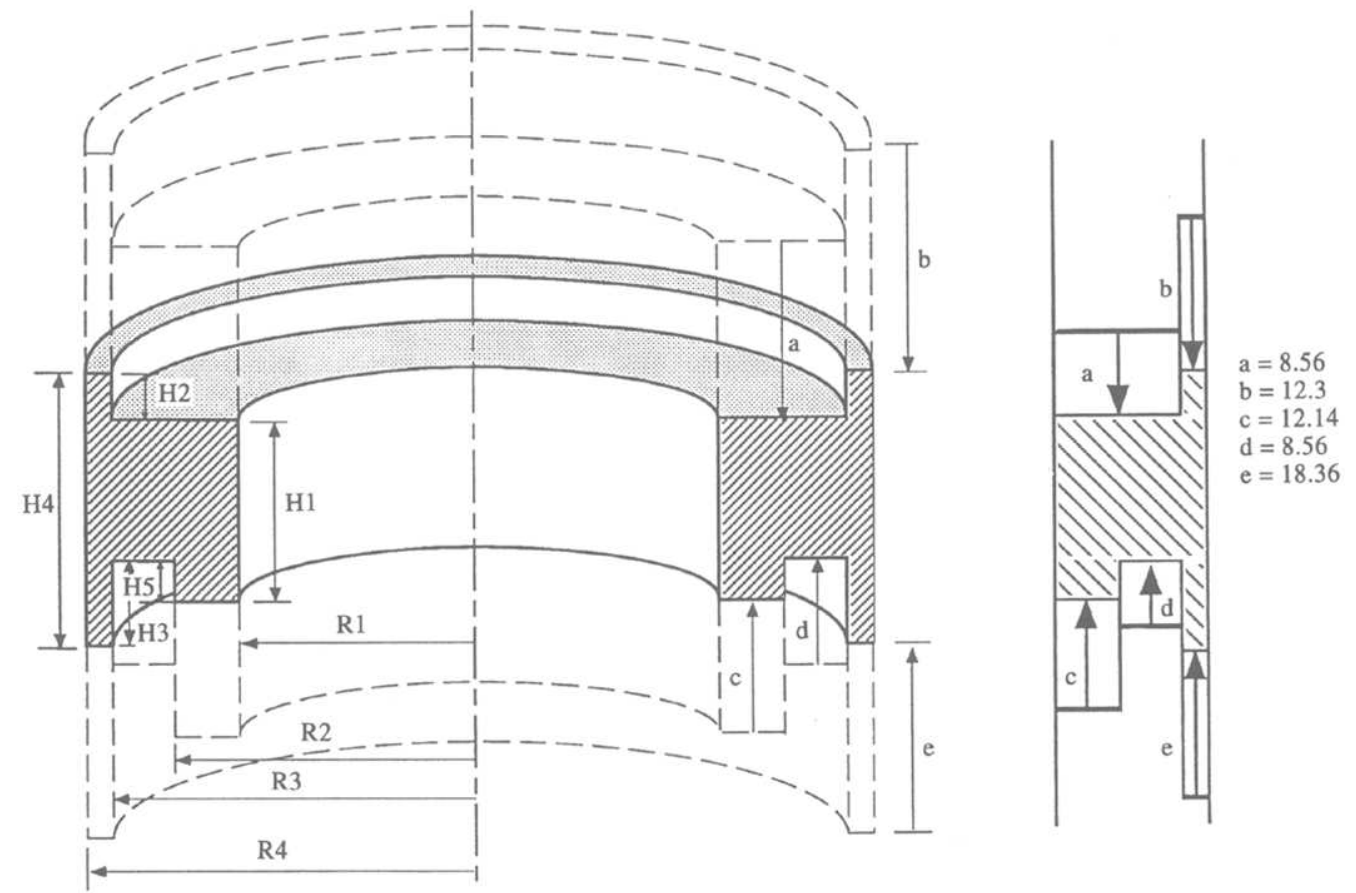

Fig. 8. Simulation of an industrial compaction process. Geometry and loading description.

The compaction is performed by means of the action of five punches, labelled $a, b, c, d$ and $e$ in the figure, whose corresponding displacements are the following: $a=8.56 \mathrm{~mm}, b=12.3$ $\mathrm{mm}, c=12.14 \mathrm{~mm}, d=8.56 \mathrm{~mm}$ and $e=18.36 \mathrm{~mm}$.

Once the specimen is compacted, extraction of the compact from the mould was also simulated in a second step by releasing punches $a$ and $b$ and $d$, and pushing the compact by means of punches $c$ and $e$ up to complete the extraction. The considered properties of the material are:

$$
\begin{aligned}
\text { Young's modulus } & =1.3 \times 10^{4} \mathrm{MPa} \\
\text { Poisson's ratio } & =0.37 \\
\text { Initial apparent density } & =\rho_{0}=2.94 \mathrm{gr} / \mathrm{cm}^{3} \\
\text { Solid density } & =\rho_{\mathrm{s}}=7.35 \mathrm{gr} / \mathrm{cm}^{3} \\
\text { Initial relative apparent density } & =\eta_{0}=2.94 / 7.35=0.4 \\
\text { Yield stress } & =100 \mathrm{MPa} \\
a_{1}(\eta)=\frac{1-\eta^{2}}{2+\eta^{2}}, \quad a_{2}(\eta) & =\left[\frac{\eta-\eta_{0}}{1-\eta_{0}}\right]^{2.7} .
\end{aligned}
$$

Friction effects are considered through a Coulomb's friction model with a friction coefficient $\mu=0.1$.

Figure 9 shows the evolution of the density at different stages of the compaction step. It can be observed to be a fairly uniform density evolution, as corresponds to a well designed compaction process. Figure $10 \mathrm{a}-\mathrm{c}$ corresponds to the predicted residual stress states after the compact extraction showing typical stress concentrations around the inner corners. Finally, Fig. 10d, shows the predicted final shape (amplified 25 times) exhibiting radial and vertical spring-back.

\section{CONCLUDING REMARKS}

Closing this work the following comments about the presented approach should be made : 

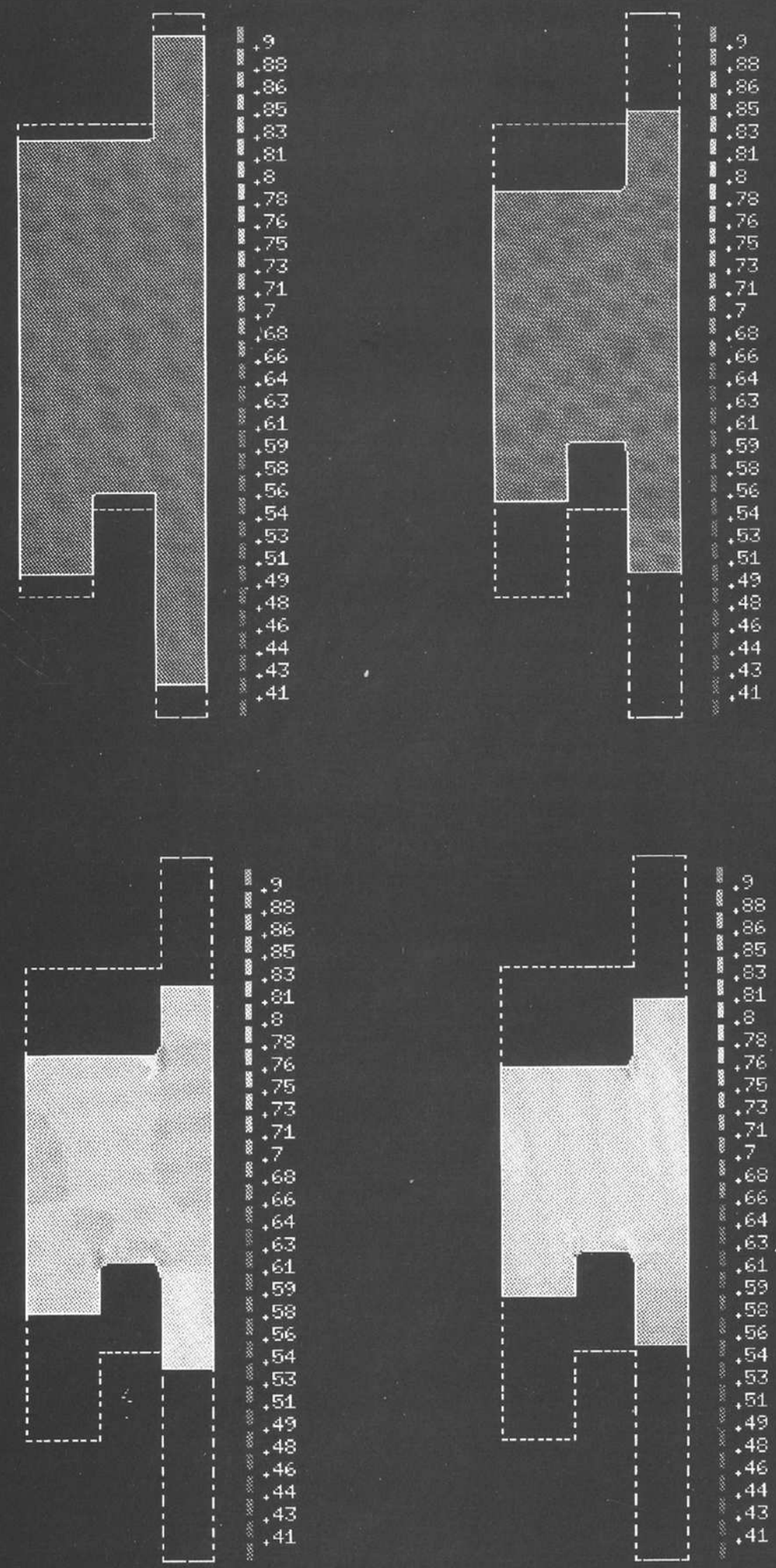


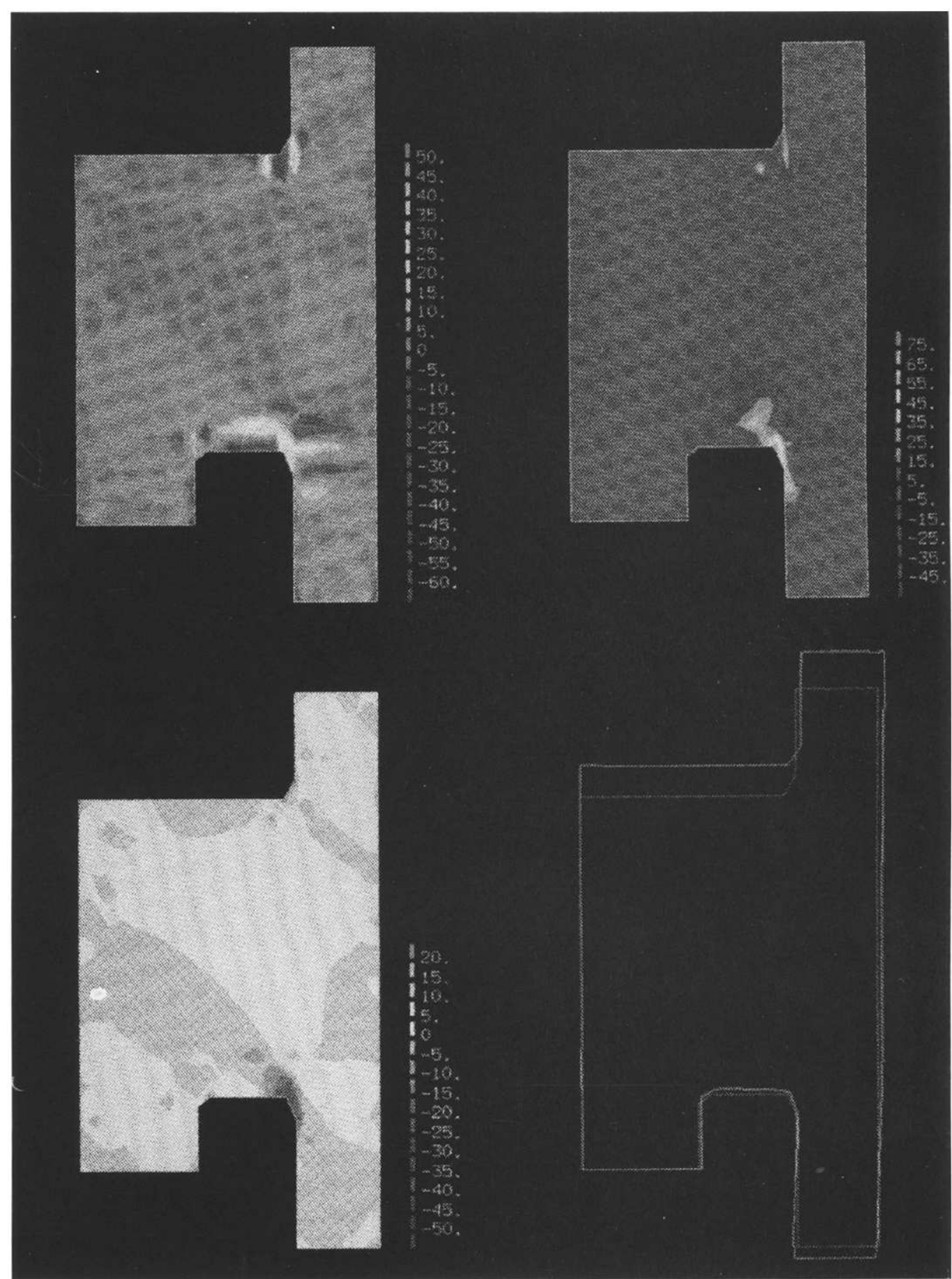

(c)

(d)

Fig. 10. Simulation of an industrial compaction process. Predicted residual stress states: (a) radial stress, (b) axial stress, (c) shear stress, (d) predicted final shape (amplified 25 times). 
- It is stated in a solid mechanics environment using a material (Lagrangian) description. Although the raw material, a very fine powder, resembles a fluid, which could induce to resort to Eulerian descriptions (Jinka et al., 1992; Brekelmans et al., 1991), it is the opinion of the authors that a Lagrangian approach has several computational advantages. In fact, compressibility of the material and, consequently, evolution of the density play a fundamental role in the process and cannot be neglected at all. In a Lagrangian description mass conservation can be stated locally in a closed form (see eqn 11), thus not enlarging the number of unknowns of the discretized system of equations to be solved. In an Eulerian description, however, mass conservation is locally stated through the continuity equations which have to be numerically integrated adding up to a new non-linear equation (due to convective terms) to the discretized system of equations that rules the problem.

- Large strain plasticity has proved to be able to capture the most relevant features of the compaction process. Evolution of the material compressibility can be modelled through a quite simple (two parameters) yield surface and appropriated flow rules. Concerning this point, an associated flow rule has shown a much better behaviour, fitting experimental results, than the non-associated one, at least for the types of metallic powder considered in this work. If this can be generalized to other non-metallic types of powder is an open question.

- Special care has been taken in computational aspects of the model. Due to the hyperelastic character of the elastic response, and since the proposed flow rules can be integrated in closed form, consistent tangent operators can be easily derived. The experiences of the authors in simulation of some real compaction processes have shown that the use of such operators is crucial to keep quadratic convergence and, thus, the required computational time small enough. As the model is envisaged to be used for design of industrial compaction processes based on trial and error procedures, this fact becomes extremely relevant.

Acknowledgement -Support of the Spanish "Comision Interministerial de Ciencia y Tecnologia" (CICYT) under grant no. MAT91-1158 is gratefully acknowledged.

\section{REFERENCES}

Abouaf, M. (1985). Modélisation de la compactacion de poudres métalliques frittées these presentée à L'Universite Scientifique et Medicale et L'Institut National Polytechnique de Grenoble.

Abraham, R., Marsden, J. E. and Ratiu (1983). Manifolds, Tensor Analysis and Application. Addison-Wesley, MA.

Akisaya, A. R., Cocks, A. C. F. and Fleck, N. A. (1994). The role of contact-contact interaction in the densification of powders. Powder Metallurgy 94, World Congress, Paris, 4-10 June, pp. 757-760.

Arunachalam, V. S. and Roman, O. V. (1990). Powder Metallurgy (Edited by V. S. Arunachalam and O. V. Roman). Aspect, India.

Bandstra, J. P., Otto, W. L. and Massa, T. R. (1990). Finite element simulation of cold die compaction leading to sintered part dimension control. In Advances in Powder Metallurgy Proc. 1990 Powder Metallurgy Conf. Exhib. (Metal Powder Industries Federation), pp. 181-196.

Brekelmans, W. A. M., Janssen, J. D. and Van De Ven, A. A. F. (1991). An Eulerian approach for die compaction processes. Int. J. Num. Meths Engng 31, 509-524.

Cante, J. C. (1995). Simulación numérica de procesos de compactación de pulvimateriales. Aplicación de técnicas de cálculo paralelo. Ph.D. Thesis, Universitat Politècnica de Catalunya, Spain.

Chenot, J. L., Bay, F. and Fourment, L. (1990). Finite element simulation of metal powder forming. Int. J. Num. Meths Engng 30, 1649-1674.

Coccoz, G., Bellet, M., Lécot, R., Ackermann, L. and Haggblad, H. (1994). Cold compaction of iron powder: experiments and simulation. Powder Metallurgy 94, World Congress, Paris, 4-10 June, pp. 709-712.

Curnier, A. (1984). A theory of friction. Int. J. Solids Structures 20,637-647.

Dixon, R. H. T. and Clayton, A. (1971). Powder Metallurgy for Engineers. Machinery Publishing, England.

Dorémus, P., Geindreau, C., Martin, A., Lécot, R. and Dao, M. (1994). High pressure triaxial apparatus for investigating the mechanical behaviour of metal powders. Powder Metallurgy 94, World Congress, Paris, 4-10 June, pp. 733-736.

Ernst, E. and Barnekow, D. (1994). Pressure, friction and density during axial powder compaction. Powder Metallurgy 94, World Congress, Paris, 4-10 June, pp. 673-676.

Gethin, D. T. and Lewis, R. W. (1994). Finite element modelling of powder compaction and its experimental validation. Powder Metallurgy 94, World Congress, Paris, 4-10 June, pp. 689-692.

Gethin, D. T., Lewis, R. W., Tran, D. V. and Ashoka, J. G. (1992). Finite element simulation in metal powder die compaction. Proceedings of the 1992 Powder Metallurgy World Congress P2 (92-V2), pp. 11-27.

Jinka, A. G. K., Lewis, R. W. and Gethin, D. T. (1992). Finite element simulation of powder compaction via the flow formulation. Proc. 1992 Powder Metallurgy World Congress, Chicago, 1991, published by MPIF. 
Krauss, T. M., Petrus, G. J. and Ferguson, B. L. (1991). Die compaction process design Part 2 : FEM simulation. Proceedings of the 1991 Powder Metallurgy Conf. Exhibition 91-V1, pp. 111-122.

Kröner, E. (1960). Arch Ration. Mech. Anal. 4, 273.

Kuhn, H. A. and Downey, C. L. (1971). Deformation characteristics and plasticity theory of sintered powder materials. Int. J. Powder Metallurgy 7, 15.

Laursen, T. A. and Simo, J. C. (1993). Algorithmic symmetrization of Coulomb frictional problems using augmented Lagrangians. Computer Meths in Applied Mech. Engng 68, 133-146.

Lee, E. H. and Liu, D. T. (1967). Finite strain elastic-plastic theory particularly for plane wave analysis. J. Appl. Phys., 38.

Lubliner, J. (1990). Plasticity Theory. Macmillan, NY.

Mandel, J. (1972). Plasticité Classique et Viscoplasticité (CISM, Udine, 1971) Springer, Vienna.

Oliver, J., Oller, S. and Cante, J. C. (1992). Numerical simulation of uniaxial compaction processes in powder materials. Proceedings of the International Congress on Numerical Methods in Engineering and Applied Sciences, Chile, 16-20 Nov., pp. 1277-1286.

Riera, M. D., Miralles, A., Cugat, G. and Prado, J. M. (1993). Modelizacion del Proceso de Compactacion en Frío de Polvos Metálicos. II Congreso de Métodos Numéricos en Ingeniería 1993, pp. 1546-1555.

Sands, R. L. and Shakespeare, C. R. (1966). Powder Metallurgy. Newnes International Monographs on Mat. Science and Tech., England.

Shima, S. and Oyade, M. (1976). Plasticity theory for porous metals. Int. J. Mech. Sci. 18, 285.

Simo, J. C. and Hughes, T. J. R. (1986). Elastoplasticity and Viscoplasticity, Computational Aspects. Stanford Univ. Depart. of Appl. Mech.

Simo, J. C. (1988a). A framework for finite strain elastoplasticity based on maximum plastic dissipation and the multiplicative decomposition: Part 1. Continuum formulation. Computer Methods in Applied Mechanics and Engineering 66, pp. 199-219.

Simo, J. C. (1988b). A framework for finite strain elastoplasticity based on maximum plastic dissipation and the multiplicative decomposition: Part 2. Computation aspects. Computer Methods in Applied Mechanics and Engineering 68, pp. 1-31.

Simo, J. C. and Laursen, T. A. (1992). An augmented Lagrangian treatment of contact problems involving friction. Computers Structures 42, 97-116.

Tamura, S., Mitsuno, T. and Aizawa, T. (1994). Powder pressing design analysis by the granular model simulation. Powder Metallurgy 94, World Congress, Paris, 4-10 June, pp. 753-756.

Trassoras, K. J., Tony, M. and Ferguson, B. L. (1989). Modeling of powder compaction using the finite element method. Proceedings of the 1989 Powder Metallurgy Conf. Exhibition V1, pp. 85-104.

Turner, C. D. (1994). A micromechanical model of multiaxial powder densification. Powder Metallurgy 94, World Congress, Paris, 4-10 June, pp. 713-716.

Weber, G. G. and Brown, S. B. (1990). Simulation of the compaction of powder components. Department of Materials Science and Engineering, Massachusetts Institute of Technology, Cambridge. 